\title{
Behavior of metallic trace elements containing in stabilized and solidified oily petroleum sludge
}

\author{
Dihia Bellache ${ }^{1}$, Karim Moussaceb ${ }^{1}$, Emmanuel Jousseinn $^{2}$, Jean-Claude Bollinger ${ }^{2}$ \\ and Loubna Chaabane ${ }^{1}$ \\ ${ }^{1}$ Materials Technology and Process Engineering Laboratory (LTMGP), Faculty of Technology, University A/MIRA Bejaia, \\ Targa-Ouzemour road, Bejaia 06000, Algeria \\ ${ }^{2}$ University of Limoges, PEREINE EA 7500 GRESE, University of Limoges, 123 avenue Albert Thomas, Limoges 87060 , \\ France
}

Article info

Article history:

Received: $12^{\text {th }}$ April 2019

Accepted: $3^{\text {rd }}$ September 2019

\section{Keywords:}

Leaching tests

Portland cement

Stabilization/solidification.

Waste

\begin{abstract}
The present work examines the influence of the leaching conditions on the release of various chemical elements from a cementitious material obtained by solidification of an industrial waste rejection of Algeria. Toxicity Characteristic Leaching Procedure (TCLP), X-ray diffraction (XRD) and Scanning electron microscopy coupled with energy dispersive X-ray microanalysis SEM-EDX analyses were employed to characterize the waste and the stabilized/solidified materials. Than several formulations were prepared with different percent of waste ranging from $0 \%$ to $30 \%$. To evaluate the influence of leaching conditions on the release of chemical ions $\left(\mathrm{Zn}^{2+}, \mathrm{Pb}^{2+}, \mathrm{Cl}^{-}, \mathrm{Mg}^{2+}, \mathrm{Ca}^{2+}, \mathrm{Na}^{+}, \mathrm{K}^{+}\right.$and $\left.\mathrm{SO}_{4}{ }^{2-}\right)$ contained in the stabilized and solidified materials, the Acid Neutralization Capacity (ANC), the Pore Water (PW) and Monolith Leaching Tests (MLT) have been carried out. The leaching tests (ANC, PW and MLT) have shown a low metal leachability. However, the lowest released amount was observed for the MLT.
\end{abstract}

\section{Introduction}

Each year, industrial activities produce large amounts of waste. These contain toxic metallic elements; their presence is a global concern due to possible adverse effects on environment (Järup 2003). Among the most used methods for treatment of oily thank bottoms sludge we find the Stabilization/Solidification (S/S) process. S/S with hydraulic binder basically involves waste containment within a solid matrix using cement for potentially toxic metals immobilization. This matrix improves high mechanical strength, capacity of retention of metal elements and low permeability and durability (Conner 1990).
These works focused on the influence of test conditions on the release of chemical species, such as formulations conditions, material composition, leachate properties (acid, base or demineralized water) (Moussaceb et al. 2012, 2013; Belebchouche et al. 2015). Works conducted by other researchers on oily petroleum sludge $\mathrm{S} / \mathrm{S}$ materials, for example, Athanasios et al. (2007) reported that $\mathrm{I} 42.5$ cement is a good bender for immobilization of fluoranthene, and benzo $[a]$ pyrene, anthracene, benzo[ $b]$ fluoroanthene and benzo[ $k]$ fluoroanthene, acenaphthene, benzo[ $a]$ anthracene. Addition of I42.5 cement reduces naphthalene and dibenzo[ $[a, h]$ anthracene leachability. 
This work revealed that leaching behavior of metals, chromate and sulfate is controlled by formation of ettringite. While $\mathrm{pH}$, pore solution and acid buffering capacity is controlled by Portlandite (Athanasios et al. 2008). Minocha et al. (2003) reported that the organic composition (grease and phenol) of the oily petroleum sludge interfered the mechanical characteristics of the S/S materials. Nestle et al. (2001) concluded that toluene, cyclooctanol and hexanol delayed cement hydration.

The petroleum exploitation, at the production level as well as at the refining process, produces important amounts of oily wastes that have an emulsified mud appearance; they are called slops oils and sludge oils, and can have very different compositions with varying proportions of water and solids. The storage of slop oil and sludge oil is conventionally in large oil lagoons where they can lead to potential environmental hazards. The objectives of our study are to characterize the properties of such a waste sample, then to evaluate the efficiency of its S/S treatment by hydraulic binders (cement). Several formulations were used (cement + waste + water), with various weight percentages of raw waste, to flow the influence of various leaching tests on the leachability of selected ions $\left(\mathrm{Zn}^{2+}, \mathrm{Pb}^{2+}, \mathrm{Fe}^{2+}\right.$ $\mathrm{Mg}^{2+}, \mathrm{Ca}^{2+}, \mathrm{Na}^{+}, \mathrm{K}^{+}, \mathrm{Cl}^{-}$and $\left.\mathrm{SO}_{4}{ }^{2-}\right)$. Here we applied the US-EPA Toxicity Characteristic Leaching Procedure (TCLP) (U.S.E.P.A. 1994).

\section{Experimental}

\section{Materials and formulation}

As the waste to be treated by $\mathrm{S} / \mathrm{S}$, we selected slop oil and sludge oil arising from petroleum storage tanks; they were produced at the 'Terminal Marin Centre Bejaia', a subsidiary of Sonatrach (the public Algerian society devoted to petroleum exploitation) dealing with storage and exportation of the raw petroleum extracted in the south of Algeria. Our sample was taken off with a shovel at the corresponding storage landfill site; its appearance is as a sludge, whose properties are given results and discussion.

The binder material used in the formulations of the S/S solids is a Portland cement (CEM I).
It was mixed with our waste sample at different mass fractions, with addition of a volume of ultrapure water at water/cement ratio $=0.5$. The amounts of each constituent in the formulation are given in Table 1. The mixtures were then molded in prismatic molds of $4 \times 4 \times 16 \mathrm{~cm}$. Samples were stored at $20 \pm 1{ }^{\circ} \mathrm{C}$ and $90 \%$ relative humidity before leaching tests at 7 and 28 days of cure.

Table 1. Concentration of chemical species in the raw sludge.

\begin{tabular}{lccr}
\hline $\begin{array}{l}\text { Formulation } \\
\text { designation }\end{array}$ & $\begin{array}{c}\text { Cement } \\
{[\mathbf{g}]}\end{array}$ & $\begin{array}{c}\text { Water } \\
{[\mathbf{g}]}\end{array}$ & $\begin{array}{c}\text { Sludge } \\
{[\mathbf{g}]}\end{array}$ \\
\hline F00 \% & 1,350 & 675 & 0 \\
F05\% & 1,350 & 675 & 101.25 \\
F7.5 \% & 1,350 & 675 & 151.875 \\
F10\% & 1,350 & 675 & 202.5 \\
F15\% & 1,350 & 675 & 303.75 \\
F20\% & 1,350 & 675 & 405 \\
F25 \% & 1,350 & 675 & 506.25 \\
F30 \% & 1,350 & 675 & 607.5 \\
\hline
\end{tabular}

\section{Mechanical strengths}

According to the NF EN 196-1 (2006) standard, compressive and bending strengths were measured on prismatic samples $(4 \times 4 \times 16) \mathrm{mm}^{3}$, using a press of type $65-\mathrm{L} 11 \mathrm{M} 2$.

\section{Methods and tests}

\section{Analytical methods}

Mineralogical phases of materials were assessed by X-ray Diffraction (Expert Prof Pan Analytical). The Scanning Electron Microscope coupled to Energy Dispersive X-ray microanalysis was used to determine the elemental composition of the oily petroleum sludge to quantify the concentration of metals in leachate the atomic absorption spectrophotometry analysis was used.

\section{Toxicity Characteristic Leaching Procedure}

The Toxicity Characteristic Leaching Procedure (TCLP) measures the potential of a waste or stabilized waste to release contaminants to the environment (U.S.E.P.A. 1994). All TCLP experiments were carried out in $250 \mathrm{~mL}$ 
Erlenmeyer flasks with $10 \mathrm{~g}$ of oily petroleum sludge or solidified sludge (28 days of cure) and $200 \mathrm{~mL}$ of the extraction solution: $5.7 \mathrm{~mL}$ of acetic acid and $64.3 \mathrm{~mL}$ of $1 \mathrm{M}$ sodium hydroxide, diluted to a volume of $1 \mathrm{~L}, \mathrm{pH}=$ $4.93 \pm 0.05$. The tests ran under continuous stirring (10 reversals per minute) at room temperature $\left(23 \pm 1{ }^{\circ} \mathrm{C}\right.$ ) for $18 \pm 2$ hours. After filtration (filter porosity: $45 \mu \mathrm{m}$ ), the leachate was analyzed using: AAS for the metallic elements (lead, nickel, chromium, calcium, iron, cadmium), the Mohr method for chloride and ultraviolet spectrophotometry for sulfate.

\section{Acid Neutralization Capacity test}

The objective of the acid neutralization capacity (ANC) test is to monitor the influence of $\mathrm{pH}$ on the leachability of chemical elements. The sample specimens were crushed and ground to reduce their particle size to less than $1 \mathrm{~mm}$. A series of samples (10 $\mathrm{g}$ each) are allowed to contact with a series of $200 \mathrm{~mL}$ of demineralized water solutions with different $\mathrm{pH}$ : in order to cover a wide $\mathrm{pH}$ range $(2-13)$, we used nitric acid and sodium hydroxide. At the end of the contact time ( 7 days of continuous stirring) the solutions were filtered (filter porosity: $45 \mu \mathrm{m}$ ) and were analyzed (Moussaceb et al. 2012).

\section{Pore Water test}

The pore water test (PW) is used to study the evolution in the composition of solutions at steady-state with the variation of the Liquid/Solid ratio (L/S) and by extrapolating the obtained curves to $\mathrm{L} / \mathrm{S}$ infinite. They also provide access to the concentrations of highly soluble elements initially contained in the saturated pore water. The samples were crushed to obtain grains of sizes $<1 \mathrm{~mm}$, then immersed in demineralized water with different $\mathrm{L} / \mathrm{S}$ ratios: $200 ; 100 ; 50 ; 10 ; 5$ and $2 \mathrm{~mL}^{-\mathrm{g}^{-1}}$ (of dried material). The tests ran under continuous stirring (10 reversals per minute) at room temperature $\left(23 \pm 1{ }^{\circ} \mathrm{C}\right)$ for 7 days (Moussaceb et al. 2013). Finally, the leachate was filtrated (filter porosity $0.45 \mu \mathrm{m}$ ) and analyzed using: AAS for the metallic elements (lead, nickel, chromium, calcium, iron, and cadmium), the Mohr method for chloride and ultraviolet spectrophotometry for sulfate.

\section{Monolithic Leaching Test}

The protocol of these leaching tests performed on monolithic blocks (MLT) is consistent with the one initially proposed by the French Agency for Environment and Energy Management (ADEME) (Tiruta-Barna et al. 2004; Barna et al. 2005). After 28 days of cure of cubic blocks of dimension $4 \times 4 \times 4 \mathrm{~cm}$, their masses and dimensions were measured to obtain their physical parameters, such as volume, area, equivalent area and equivalent weight. The monolithic block, put on a grid allowing leachate to flow freely, was immersed in two types of solution: demineralized water and sulfate solution $\left(0.352 \mathrm{M}\right.$ of $\left.\mathrm{Na}_{2} \mathrm{SO}_{4}\right)$ in a polyethylene flask, which was hermetically closed to prevent both air penetration $\left(\mathrm{CO}_{2}\right)$ and water evaporation during the test. A $10 \mathrm{~cm}^{3} / \mathrm{cm}^{2}$ liquid/surface ratio was maintained constant at each solution renewal. The solutions were renewed after $0.25 ; 0.75 ; 1 ; 2 ; 5 ; 7 ; 20$ and 28 days, giving a total of 64 days of continuous leaching. We thus obtained 8 solutions to be analyzed after filtration $(0.45 \mu \mathrm{m})$ in order to give the following chemical parameters: $\mathrm{pH}$, leached solution conductivity.

These MLT test results are presented graphically as a function of the contact time or the average time calculated by the Eq. 1:

$$
T_{i}=\left[\frac{\sqrt{t_{i}}+\sqrt{t_{i+1}}}{2}\right]^{2}
$$

\section{Results and Discussion}

\section{Characterization of the binder}

In this study, Portland cement CEMI was used as a binder for the waste $\mathrm{S} / \mathrm{S}$. Its chemical and physico-chemical characteristics are summarized in Table 2. The high amount of calcium in the binder will contribute to substitution of $\mathrm{Ca}^{2+}$ by the metals present in the waste, thus generating their effective trapping during the $\mathrm{S} / \mathrm{S}$ process. 
Table 2. Chemical and physical characteristics of used cement.

\begin{tabular}{lccccccccc}
\hline Element & $\mathrm{SiO}_{2}$ & $\mathrm{Al}_{2} \mathrm{O}_{3}$ & $\mathrm{Fe}_{2} \mathrm{O}_{3}$ & $\mathrm{CaO}$ & $\mathrm{MgO}$ & $\mathrm{SO}_{3}$ & $\mathrm{~K}_{2} \mathrm{O}$ & $\mathrm{Na}_{2} \mathrm{O}$ & $\mathrm{Cl}_{2}$ \\
\hline Content [\%] & 22.44 & 5.42 & 5.63 & 62.87 & 1.76 & 1.55 & 0.11 & 0.20 & 0.01 \\
\hline
\end{tabular}

fire loss = 0.96;

$\mathrm{SSB}=3,511 \mathrm{~cm}^{2} \cdot \mathrm{g}^{-1}$

specific mass $=3.35 \mathrm{~g} \cdot \mathrm{cm}^{-3}$.

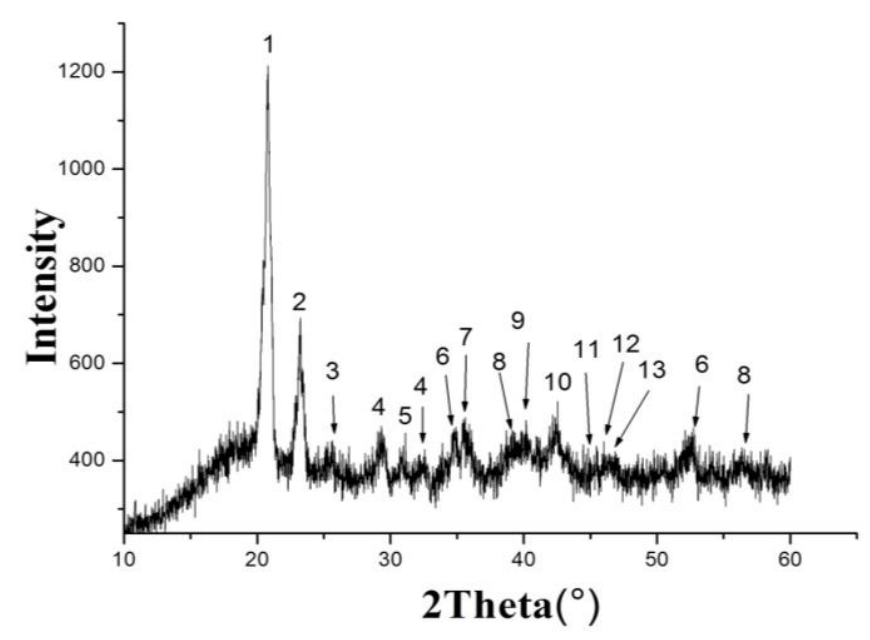

Fig. 1. XRD of the oily petroleum sludge.

\section{Characterization of the raw waste}

\section{$X$-ray Diffraction $(X R D)$}

X-ray Diffraction (XRD) is widely used to the phase identification of a crystalline material and can provide valuable information. From the XRD results (Fig. 1 and Table 3), patterns show several peaks corresponding to different minerals present in the waste sample: various complex phases containing chemical elements, such as $\mathrm{Cr}$, $\mathrm{Pb}, \mathrm{Fe}, \mathrm{S}, \mathrm{Mn}, \mathrm{Zn}, \mathrm{Si}, \mathrm{Ti}$ and $\mathrm{Cu}$. As a result, this method has highlighted the pollutant and hazardous nature of the studied waste due to the presence of toxic metals. Moreover, the presence of sulfates and the sulfides can be noted; in aqueous oxidizing media, they can generate sulfuric acid, thus an acid medium also known as 'acid drainage', supporting the dissolution of the toxic metal elements, then their release into the environment.

\section{Scanning Electron Microscopy (SEM) coupled with Energy Dispersive X-ray (EDX) microanalysis}

To determine the elemental composition of sludge, an Energy Dispersive X-ray microanalysis (EDX) coupled to the SEM (SEM-EDX, F.E.I. Quanta
Table 3. Results of the XRD analysis of the oily petroleum sludge corresponding to Fig. 1.

\begin{tabular}{lll}
\hline Peak & Mineral name & Chemical formula \\
\hline 1 & Anglesite & $\mathrm{Pb}\left(\mathrm{SO}_{4}\right)$ \\
2 & Galena & $\mathrm{PbS}$ \\
3 & Lithiophilite & $\mathrm{LiMn}\left(\mathrm{PO}_{4}\right)$ \\
4 & Nantokite & $\mathrm{CuCl}_{2}$ \\
5 & Zincmolybdate & $\mathrm{ZnMoO}_{4}$ \\
6 & Jacobsite & $\mathrm{MnFe}_{2} \mathrm{O}_{4}$ \\
7 & Zincite & $\mathrm{ZnO}$ \\
8 & Diopside & $\mathrm{CaMg}\left(\mathrm{SiO}_{2}\right)$ \\
9 & Hedenbergite & $\mathrm{CaFeSi}_{2} \mathrm{O}_{6}$ \\
10 & Titanomahnetite & $\mathrm{Fe}_{2} \mathrm{TiO}_{4}$ \\
11 & Cotunnite & $\mathrm{Cl}_{2} \mathrm{~Pb}$ \\
12 & Chromium Iodide & $\mathrm{CrI}_{3}$ \\
13 & Esperite & $(\mathrm{Ca}, \mathrm{Pb}) \mathrm{ZnSiO}_{4}$ \\
\hline
\end{tabular}

200) was applied to the raw sludge (Fig. 2). EDX diagram showed the presence of intense peaks of oxygen $\mathrm{O}$, iron $\mathrm{Fe}$, silica $\mathrm{Si}, \mathrm{Pb}$ and aluminum $\mathrm{Al}$, and other elements, such as sodium $\mathrm{Na}$, carbon $\mathrm{C}$ sulfur $\mathrm{S}$, potassium $\mathrm{K}$ and calcium $\mathrm{Ca}$. EDX results showed that the raw sludge waste contains some metals, such as $\mathrm{Zn}, \mathrm{Pb}$ and $\mathrm{Fe}$.

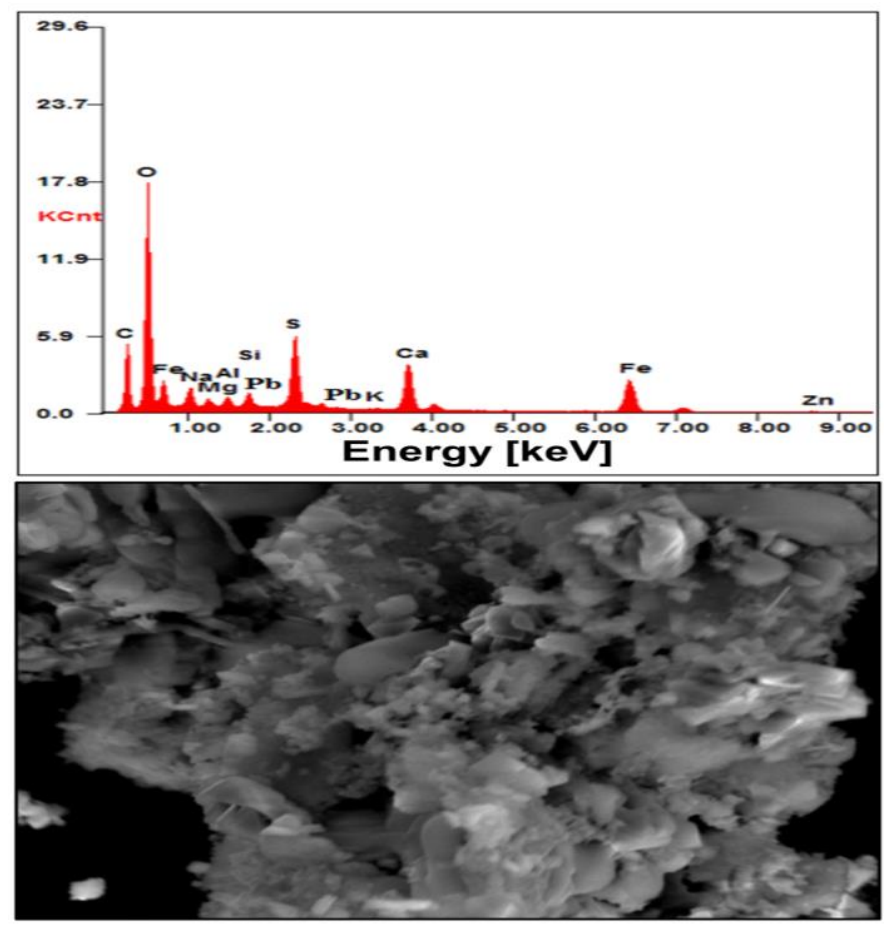

Fig. 2. SEM-EDX analysis the oily petroleum sludge. 
Table 4. Concentration of chemical species in the raw sludge.

\begin{tabular}{lllllllll}
\hline Element & $\mathbf{Z n}^{2+}$ & $\mathbf{F e}^{2+}$ & $\mathbf{P b}^{2+}$ & $\mathbf{N i}^{2+}$ & $\mathbf{C u}^{2+}$ & $\mathbf{C o}^{2+}$ & $\mathbf{C d}^{2+}$ \\
\hline Concentration $\left[\mathbf{m g . k g}{ }^{-1}\right]$ & 5,321 & 78.01 & 2,635 & 3.16 & 3.24 & 1.71 & 3.25 \\
\hline Element & $\mathbf{K}^{+}$ & $\mathbf{N a}^{+}$ & $\mathbf{C a}^{2+}$ & $\mathbf{M g}^{2+}$ & $\mathbf{S O}_{4}{ }^{2-}$ & $\mathbf{C l}^{-}$ & $\mathbf{P O}^{3-}$ \\
\hline Concentration $\left[\mathbf{m g . k g}{ }^{-1}\right]$ & 690 & 60,839 & 641 & 769 & 12,161 & 45,441 & 1.51 \\
\hline
\end{tabular}

\section{Determination of metal concentration}

Leachate obtained after TCLP test was analyzed using AAS for obtaining their chemical composition (Table 4). High concentrations of $\mathrm{Zn}^{2+}, \mathrm{Pb}^{2+}, \mathrm{Cl}^{-}, \mathrm{Mg}^{2+}, \mathrm{Ca}^{2+}, \mathrm{Na}^{+}, \mathrm{K}^{+}$and $\mathrm{SO}_{4}{ }^{2-}$, were detected for a sample. $\mathrm{Pb}^{2+}, \mathrm{Na}^{+}, \mathrm{Cl}^{-}, \mathrm{SO}_{4}{ }^{2-}$ and $\mathrm{Zn}$ are the most predominant species with concentrations over $1,000 \mathrm{mg} \cdot \mathrm{kg}^{-1} \cdot \mathrm{Mg}^{2+}, \mathrm{Fe}^{2+}$, $\mathrm{Ca}^{2+}, \mathrm{K}^{+}$concentration is also relatively high: these concentrations may have originated from the tank walls as also suggested by other researchers (Gallego et al. 2007). Results on $\mathrm{Cu}$, $\mathrm{Co}, \mathrm{Ni}, \mathrm{Cd}$ recorded in Table 4 show that average concentrations of $\mathrm{Pb}$ and $\mathrm{Zn}$ are very large and far exceed the standards required (50 mg. $\mathrm{kg}^{-1}$ and $200 \mathrm{mg} \cdot \mathrm{kg}^{-1}$ respectively) by the regulations (EU Council 2003). We conclude that this raw slop oil waste must be encapsulated, for instance by $\mathrm{S} / \mathrm{S}$ with hydraulic binders, in order to reduce its pollution and its toxicity so it could be accepted for storage in specialized landfill.

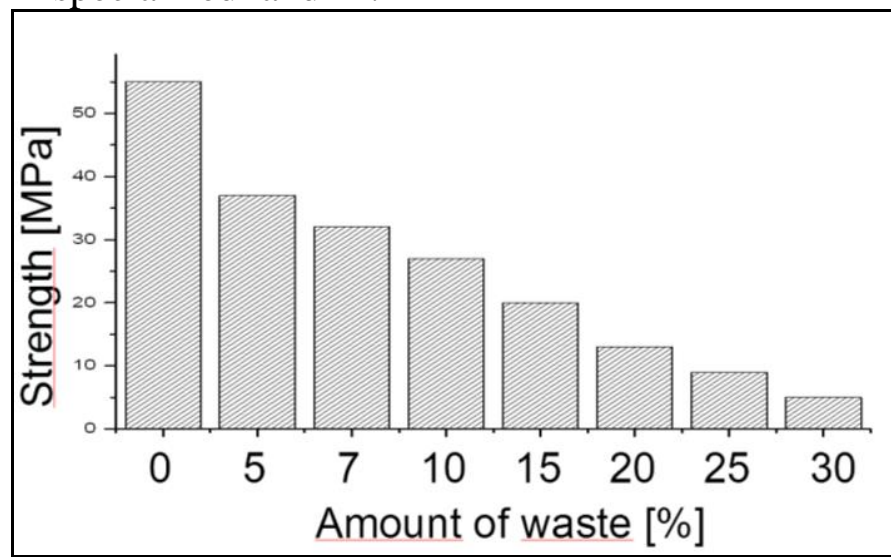

Fig. 3. Evolution of mechanical strengths according to sludge content.

\section{Characterization of Stabilized/Solidified materials}

\section{Mechanical strength}

The Fig. 3 illustrates the evolution of mechanical strengths of $\mathrm{S} / \mathrm{S}$ materials as a function of waste content.

compressive

strengths of Solidified/Stabilized materials were measured at 28 days age. Results highlight that mechanical strengths of $\mathrm{S} / \mathrm{S}$ materials are higher than minima required by the XP X31-211 (2012) standard, which are equal to $1 \mathrm{MPa}$. The mechanical strength of cement-based materials tested decreases as the mass percent of waste increases. waste addition modifies the mechanical strengths because of the presence of organic matters and heavy metals, such as $\mathrm{Zn}$. These latter affect the cement hydration, delaying mainly the hydration of $\mathrm{C}_{3} \mathrm{~S}$. The presence of waste in cementitious materials reduces also the kinetics of formation of the calcium silicate hydrates C-S-H and portlandite $\mathrm{Ca}(\mathrm{OH})_{2}$. This explains the influence of the petroleum wastes on the mechanical strengths of S/S materials used. Moreover, the high $\mathrm{pH}$ value of the pore solution during the cement hydration leads to the precipitation of lead in several forms: $\mathrm{PbSO}_{4}$, $\mathrm{PbO}, \mathrm{Pb}(\mathrm{OH})_{2}$ and a mixture $\mathrm{PbO}-\mathrm{Pb}(\mathrm{OH})_{2}$ (Imyim et al. 2000).

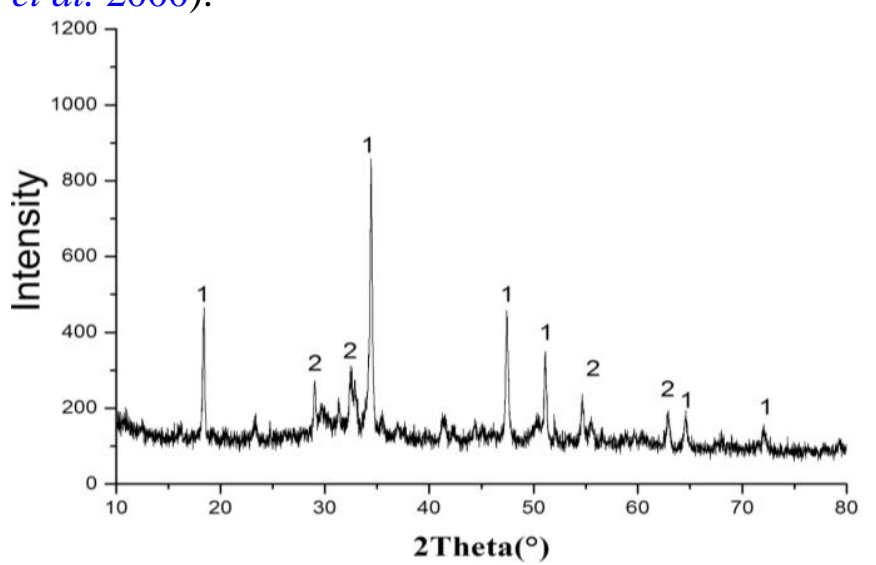

Fig. 4. $\mathrm{X}$-ray diffraction patterns of $\mathrm{F}_{0}$ at 7 days age. Peak 1 is $\mathrm{Ca}(\mathrm{OH})_{2}$ and peak 2 is ettringite.

\section{$X$-ray Diffraction $(X R D)$}

To determine the new mineralogical phases formed after $\mathrm{S} / \mathrm{S}$ of the studied waste, an XRD analysis was performed on S/S materials powders. The Fig. 4, 5 and Table 5 show XRD patterns for S/S samples, 


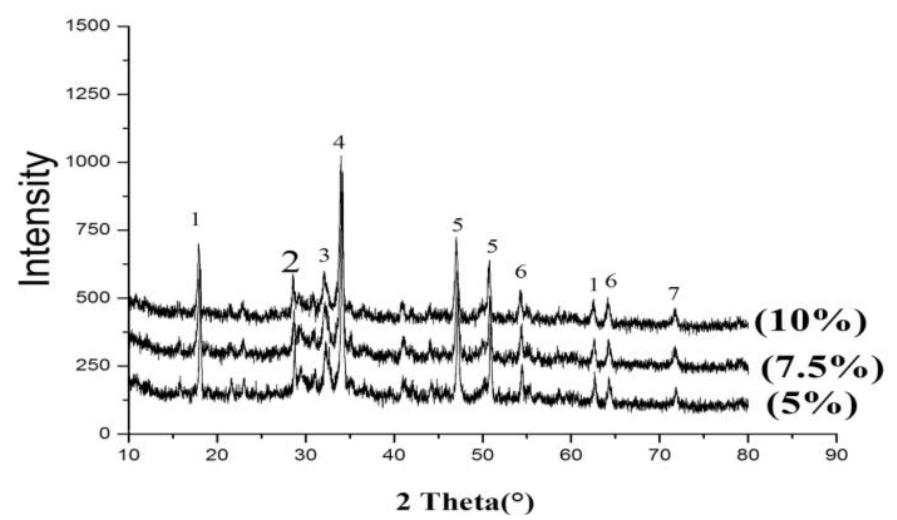

Fig. 5. X-ray diffraction patterns of F5, F7.5 and F10 at 7 days age.

Table 5. Parameters of the XRD analysis of the S/S materials.

\begin{tabular}{lll}
\hline Peak & Mineral name & Chemical formula \\
\hline 1 & Etteingite & $\mathrm{Ca}_{6} \mathrm{Al}_{2}\left(\mathrm{SO}_{4}\right)_{3}(\mathrm{OH})_{12} \cdot 26 \mathrm{H}_{2} \mathrm{O}$ \\
2 & Gunningite & $\mathrm{Zn}\left(\mathrm{SO}_{4}\right)$ \\
3 & Tephroite calcian & $(\mathrm{Mn}, \mathrm{Ca})_{2}\left(\mathrm{SiO}_{4}\right)$ \\
4 & Lead Hydroxide & $\mathrm{Pb}(\mathrm{OH})_{2}$ \\
5 & Cerussite & $\mathrm{Pb}\left(\mathrm{CO}_{3}\right)$ \\
6 & FeMn Silicate & $\mathrm{FeMn}\left(\mathrm{SiO}_{4}\right)$ \\
7 & Portlandite & $\mathrm{Ca}(\mathrm{OH})_{2}$ \\
\hline
\end{tabular}

the spectra were analyzed by the X'Pert High Score software. As expected, the major crystalline phases present in $\mathrm{F}_{0}$ are cement hydrates, such as portlandite $\mathrm{Ca}(\mathrm{OH})_{2}$ and ettringite $\mathrm{Ca}_{6} \mathrm{Al}_{2}\left(\mathrm{SO}_{4}\right)_{3}(\mathrm{OH})_{12} \cdot 26 \mathrm{H}_{2} \mathrm{O}$ (Fig. 4). The new solid phases formed during $\mathrm{S} / \mathrm{S}$ of our slop waste are very complex; a comparison between the patterns of Fig. 6 revealed that all peaks shapes are similar for different matrix of $\mathrm{S} / \mathrm{S}$ materials $(5 \%, 7.5 \%$ and $10 \%)$ but with different intensity.

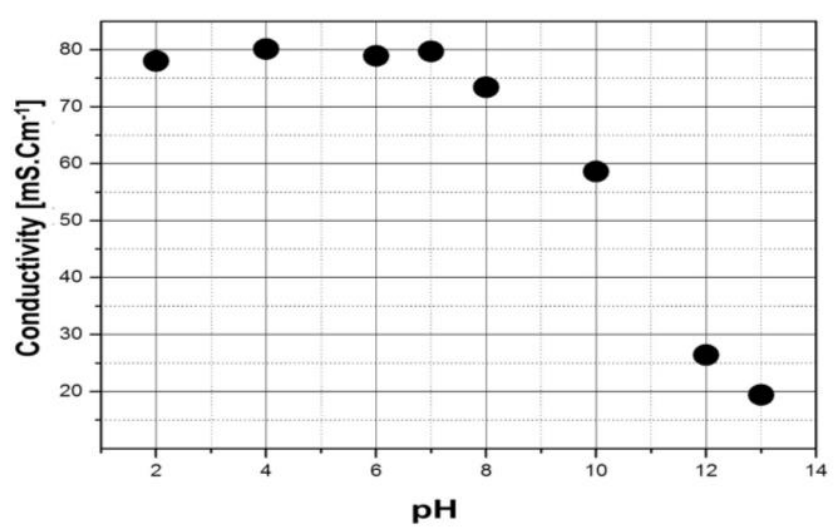

Fig. 6. Electrical conductivity as a function of $\mathrm{pH}$.

We can also observe the disappearance of the peaks of the initial metal-containing phases compared to the XRD diagram of raw waste (Fig. 1). This means that these metals are bound as complexes or present as amorphous phases (Polettini et al. 2001). Several studies have shown that metals can be fixed in a crystallized structure as metal-hydrated phases, metal hydroxides and calcium-metal compounds, or be immobilized by physical entrapment into the $\mathrm{C}-\mathrm{S}-\mathrm{H}$ cement phase (Kazuyuki and Yoshiro 2008; Zhang et al. 2008; Chen et al. 2009). Belite (dicalcium silicate, $\mathrm{Ca}_{2} \mathrm{SiO}_{4}$ ) was also observed, indicating the presence of some anhydrous cement grains. $\mathrm{Pb}(\mathrm{OH})_{2}$ was detected due to the basic solution present during the hydration of cement that supports the substitution of $\mathrm{Ca}$ in portlandite with $\mathrm{Pb}$ (Van der Sloot et al. 2006). This result highlights the efficiency of the $\mathrm{S} / \mathrm{S}$ process in trapping heavy metals, and reducing the polluting potential of this waste.

\section{Behavior of solidified/stabilized materials}

\section{Acid Neutralization Capacity (ANC) test}

Solidified waste samples were equilibrated with water at different $\mathrm{pH}$ values; the ANC test results show conductivity and the concentrations of several ionic species: $\mathrm{Pb}^{2+}, \mathrm{Zn}^{2+}, \mathrm{Fe}^{2+}, \mathrm{Na}^{+}, \mathrm{SO}_{4}{ }^{2-}$ and $\mathrm{Cl}^{-}$ (Fig. 6 and 7, respectively). Starting from $\mathrm{pH} \approx 7$, there is a decrease in the electrical conductivity as a function of $\mathrm{pH}$ (Fig. 6); this decrease may be due to the formation of (in)soluble complexes from the ionic species contained in the solution.

Behavior of lead, zinc and iron (amphoteric metals) strongly depends on the leachate $\mathrm{pH}$ (Fig. 7). The minimum of solubilization of $\mathrm{Zn}$ and $\mathrm{Fe}$ are located at $\mathrm{pH} \approx 10$. Their presence as oxides and hydroxides was expected (especially amorphous lead hydroxides). S/S materials leached the maximum amount of $\mathrm{Pb}, \mathrm{Zn}$ and $\mathrm{Fe}$ at $\mathrm{pH}=2$.

The solubility of $\mathrm{Ca}$ is strongly $\mathrm{pH}$-dependent; $\mathrm{Ca}$ concentration decreases rapidly with the increase of $\mathrm{pH}$. The release appears to be controlled by the dissolution of soluble solid phases containing $\mathrm{Ca}$, such as portlandite $\mathrm{Ca}(\mathrm{OH})_{2}, \mathrm{C}-\mathrm{S}-$ $\mathrm{H}$ cement phase, and traces of $\mathrm{CaCO}_{3}$. It was observed a vertical bearing for very acidic $\mathrm{pH}$; this means that the $\mathrm{Ca}$ content in the different materials is completely solubilized. As expected, the solubility of $\mathrm{Na}^{+}$is almost constant with the variation of $\mathrm{pH}$ (Van der Sloot et al. 2007; Voglar and Lestan 2013). 

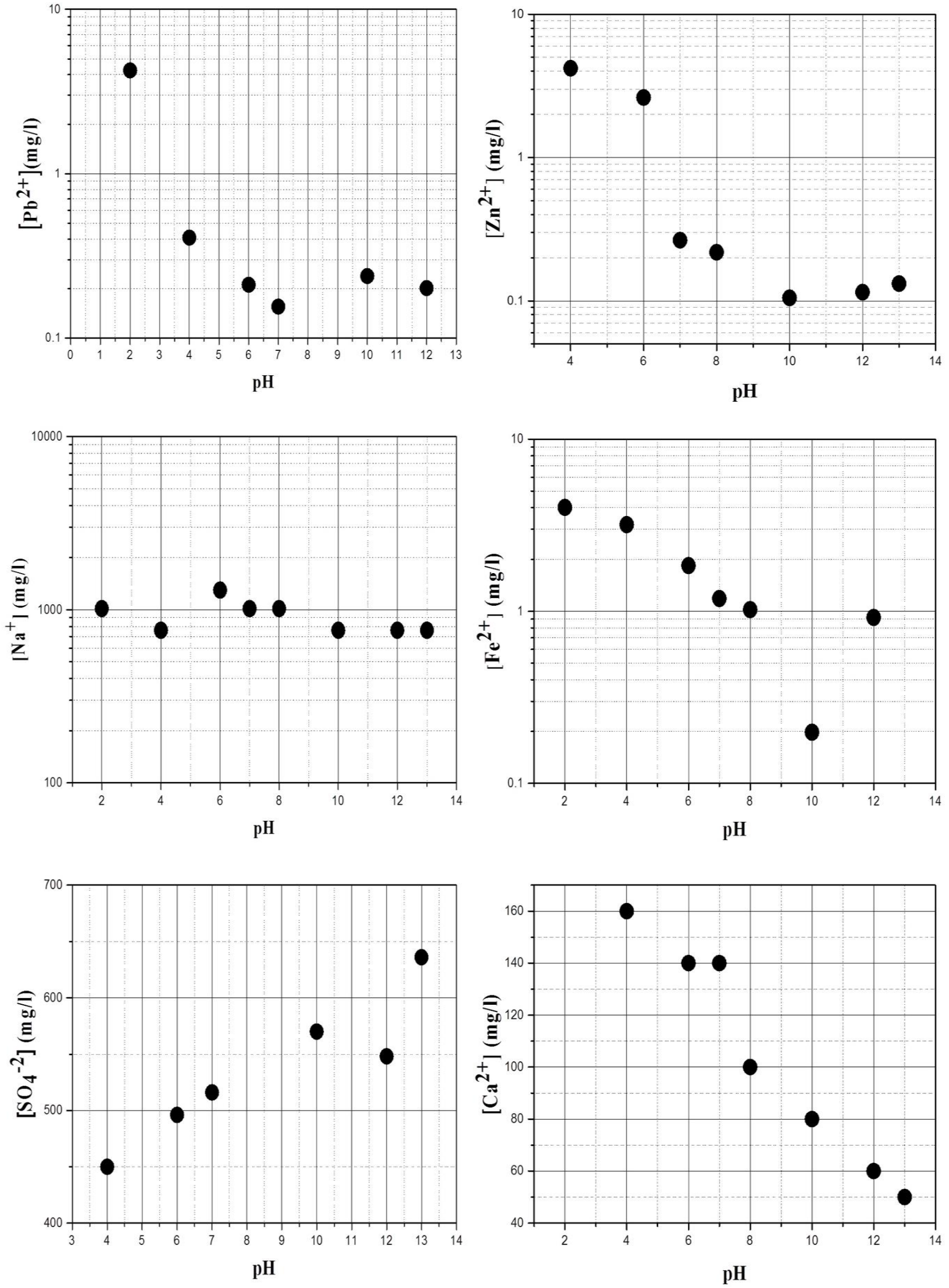

Fig. 7. Evolution of elements concentrations as a function of $\mathrm{pH}$. 

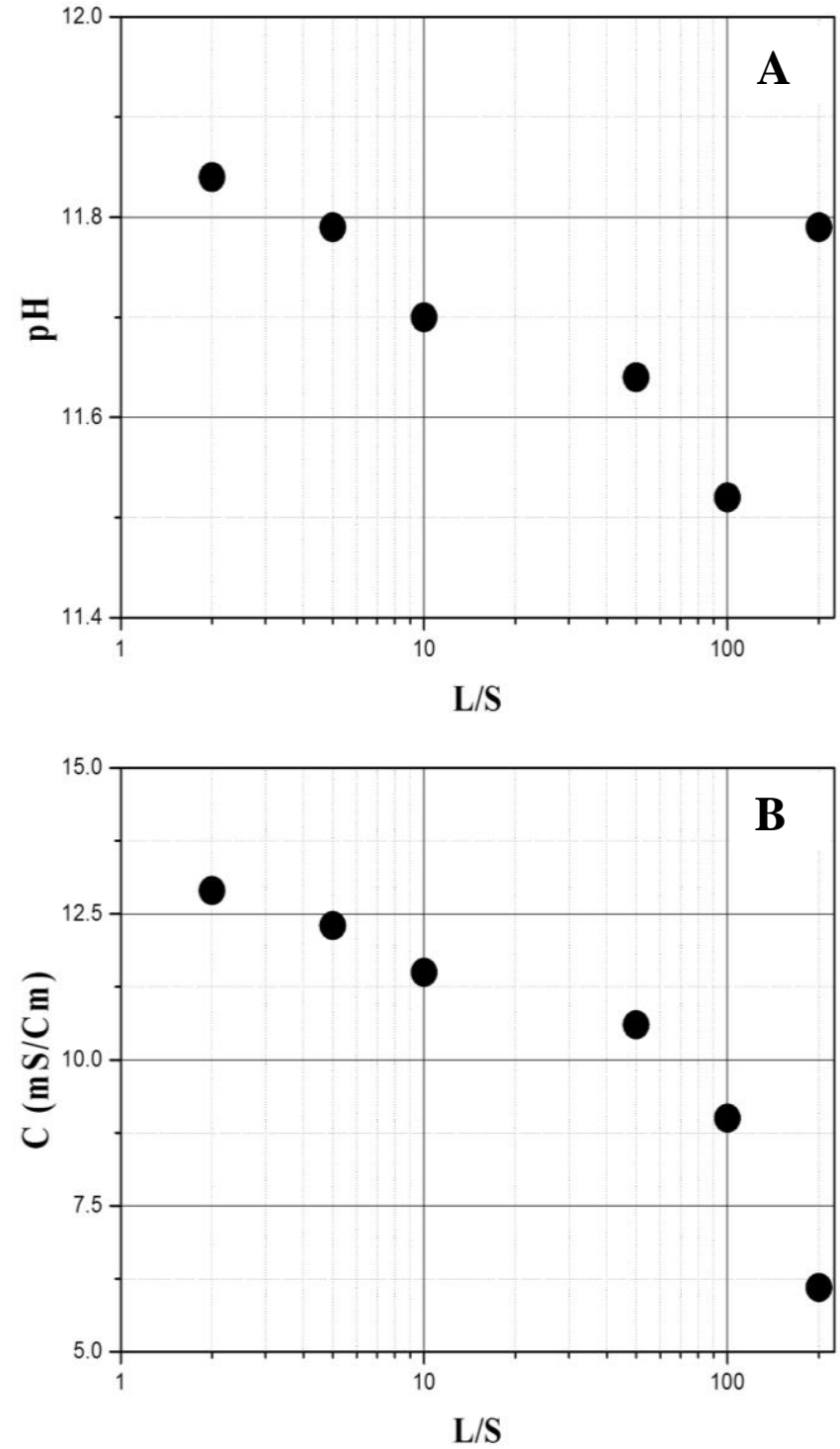

Fig. 8. Evolution of $\mathrm{pH}(\mathbf{A})$ and conductivity $(\mathbf{B})$ as function of $\mathrm{L} / \mathrm{S}$ ratio.

\section{Pore water $(P W)$ test}

Representing $\mathrm{pH}$ and conductivity versus L/S ratio (Fig. 8), as well as representing pollutant concentrations versus L/S ratio (Fig. 9), contains information on the solubility of different species including $\mathrm{Pb}^{2+}, \mathrm{Zn}^{2+}, \quad \mathrm{Na}^{+}, \quad \mathrm{Fe}^{2+}, \quad \mathrm{SO}_{4}{ }^{2-}$ and $\mathrm{Cl}^{-}$. Decrease in L/S ratio induces a decrease of conductivity, $\mathrm{pH}$ values vary between 11.52 and 11.84, these values reflects a basic medium and this may be due to the dissolution of portlandite and $\mathrm{OH}^{-}$anions liberation (Fig. 6). The solubilization of $\mathrm{Pb}^{2+}, \mathrm{Zn}^{2+}$, $\mathrm{Na}^{+}, \mathrm{Fe}^{2+}, \mathrm{SO}_{4}^{2-}$ and $\mathrm{Cl}^{-}$ions (Fig. 9) decreases with increasing of $\mathrm{L} / \mathrm{S}$ ratio. The rapid decrease in their concentrations allows one to assume that these elements came from the progressive dilution of an initial available quantity; hence, the decrease of the ratio L/S induces only an increase in leach solution's concentration.

\section{Monolithic Leaching Test (MLT)}

The cumulative flow of chemical elements versus contact time, for two types of environment (demineralized water and sulfate medium), is presented at Fig. 10 From these plots, it is obvious that the flow of chemical elements $\left(\mathrm{Pb}^{2+}\right.$, $\mathrm{Zn}^{2+}, \mathrm{Na}^{+}, \mathrm{Fe}^{+2}, \mathrm{SO}_{4}{ }^{2-}$ and $\left.\mathrm{Cl}^{-}\right)$increases with increasing of contact time in all mediums and that a steady-state is attained within 2 days of contact for both media. These curves clearly indicate that the release of the selected ions $\left(\mathrm{Pb}^{2+}, \mathrm{Zn}^{2+}, \mathrm{Na}^{+}, \mathrm{Fe}^{+2}, \mathrm{SO}_{4}{ }^{2-}\right.$ and $\left.\mathrm{Cl}^{-}\right)$ from monolithic blocs surface is a two-step process. The first step is rapid and quantitatively predominant and the second step slower and quantitatively insignificant. The rapid release of metal ions to the external medium is followed by possible slow diffusion to the exterior of the monolithic bloc. The second stage ( 2 to 64 days) can be explained by the depletion of metals ions, which are on the surface of monoliths bloc. The increase in flow is more pronounced for sulfated medium system compared to neuter medium. This may be explained by the sulfates penetrate inside the monoliths which will give rise to the ettringite which will create an increase in porosity, consequently important flow out of metals, but these quantities remain weak.

\section{Results of Toxicity Characteristic Leaching Procedure (TCLP)}

Table 6 shows that concentrations of metals from the S/S sludge material are strongly lower than the concentrations of elements leached from the raw petroleum sludge. The ratios of metals retained are approximately $98 \%$ for lead and $97 \%$ for zinc, and $93 \%$ for chloride. Process S/S applied to the waste has reduced considerably the potential release of chemical species to the environment. 
Nova Biotechnol Chim (2019) 18(2): 154-165
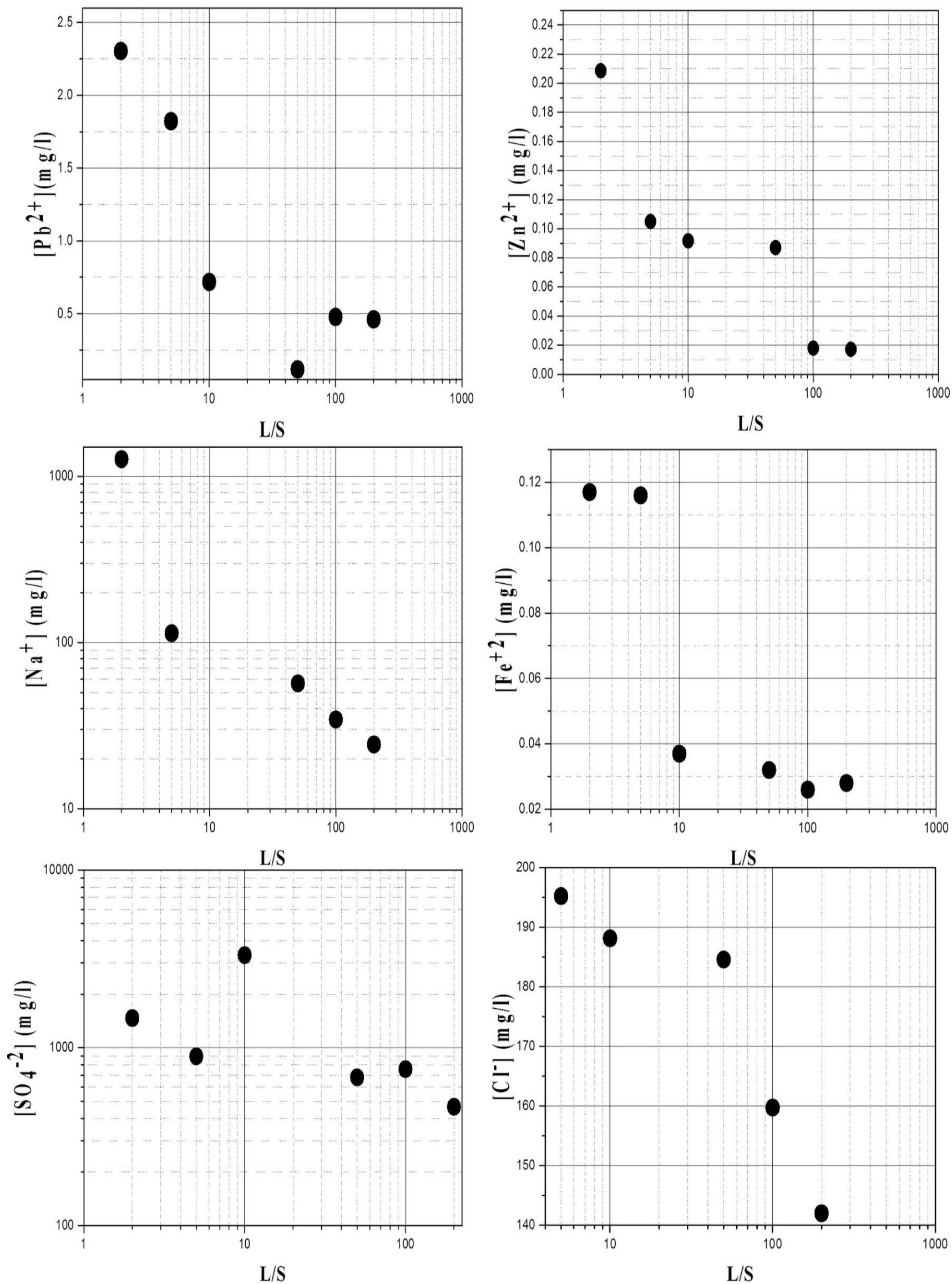

Fig. 9. Concentration of chemical species as a function of $\mathrm{L} / \mathrm{S}$ ratio. 

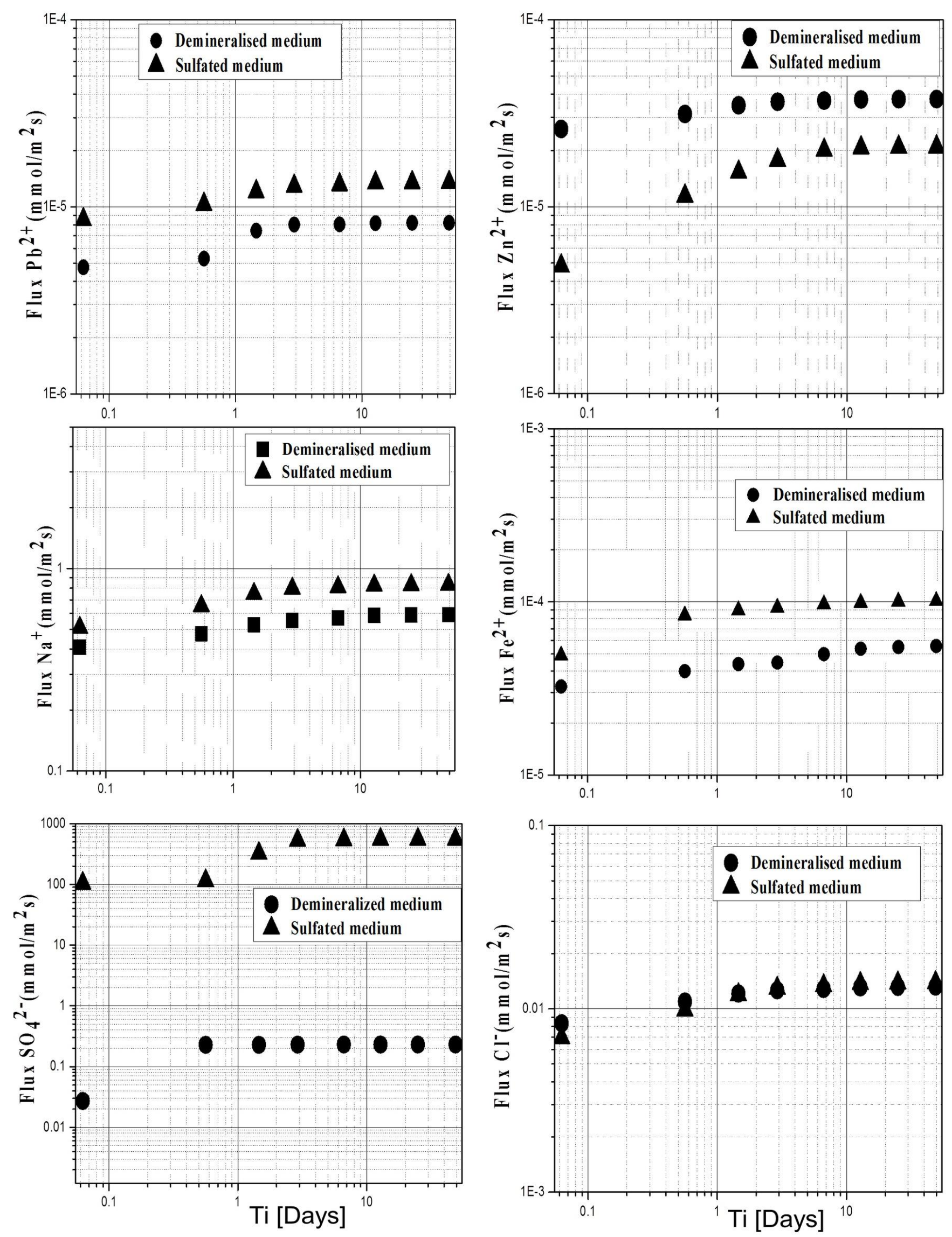

Fig 10. Flux of elements released during the Monolith Leaching Test (MLT). 
Table 6. Flux of elements released during the Monolith Leaching Test (MLT).

\begin{tabular}{ccccc}
\hline & \multicolumn{2}{c}{ Concentration } & \multicolumn{2}{c}{ Amount of species } \\
\hline & $\begin{array}{c}\text { Before S/S } \\
{\left[\mathbf{m g . L ^ { - 1 }}\right]}\end{array}$ & $\begin{array}{c}\text { After S/S } \\
{\left[\mathbf{m g . L ^ { - 1 }}\right]}\end{array}$ & $\begin{array}{c}\text { Retained } \\
{\left[\mathbf{m g . L}^{-1}\right]}\end{array}$ & $\begin{array}{c}\text { Trapped } \\
{[\%]}\end{array}$ \\
\hline $\mathbf{P b}$ & & & & \\
$5 \%$ & 131.25 & 2.32 & 128.92 & 98.23 \\
$7.5 \%$ & 131.25 & 1.43 & 129.81 & 98.90 \\
$10 \%$ & 131.25 & 2.99 & 128.26 & 97.72 \\
$\mathbf{F e}$ & & & & \\
$5 \%$ & 3.90 & 1.47 & 2.42 & 62.10 \\
$7.5 \%$ & 3.90 & 0.90 & 2.99 & 76.87 \\
$10 \%$ & 3.90 & 3.26 & 0.63 & 16.35 \\
$\mathbf{Z n}$ & & & & \\
$5 \%$ & 266 & 6.86 & 259.18 & 97.42 \\
$7.5 \%$ & 266 & 5.74 & 260.30 & 97.84 \\
$10 \%$ & 266 & 6.53 & 259.51 & 97.54 \\
$\mathbf{C l}-$ & & & & \\
$5 \%$ & 2,272 & 177.50 & $2,094.50$ & 92.18 \\
$7.5 \%$ & 2,272 & 163.30 & $2,108.70$ & 92.81 \\
$10 \%$ & 2,272 & 149.10 & $2,122.90$ & 93.43 \\
\hline
\end{tabular}

\section{Conclusions}

The present study has evaluated the treatment of petroleum sludge waste with Stabilization/Solidification by hydraulic binder (OPC). The obtained results can be summarized as follows:

The characterization of waste by X-ray Diffraction (XRD) measurements and TCLP test shows that the waste has high concentrations of $\mathrm{Pb}$, and $\mathrm{Zn}$. In fact, the studied waste is classified as hazardous waste. XRD analysis of $\mathrm{S} / \mathrm{S}$ materials highlight metals chemically bonding to the microstructure of $\mathrm{S} / \mathrm{S}$ materials, which explains the success of treatment with $\mathrm{S} / \mathrm{S}$. For more complete investigation, this hydration process can be modeled (Delmi et al. 2006). Diffusional type and leaching phenomena controls the release of chemical species from the S/S materials. Solubility values obtained show that behaviors of solubilization, elements that are $\mathrm{pH}$ dependent $\left(\mathrm{Pb}^{2+}, \mathrm{Zn}^{2+}, \mathrm{Fe}^{2+}, \mathrm{SO}_{4}{ }^{2-}, \mathrm{Ca}^{2+}\right)$. The highest amounts extracted of heavy metals are obtained by the $\mathrm{pH}-$ dependence test. TCLP results indicate that the concentrations of $\mathrm{Pb}, \mathrm{Zn}$, and $\mathrm{Fe}$ in the petroleum sludge are much higher than their concentrations in S/S materials. The mortars have a high retention efficiency of heavy metals $98 \%$. Comparative study of the four formulations of $\mathrm{S} / \mathrm{S}$ materials, mortars, showed that the S/S material mortar with $7.5 \%$ which is the best formulation for use in managing the waste since it improve good chemical and physical stability and good stability for external attacks.

\section{Conflict of Interest}

The authors declare that they have no conflict of interest.

\section{References}

AFNOR NF EN 196-1 (2006) Methods of testing cement Part 1: Determination of mechanical strengths.

AFNOR NF X31-211 (2012) Characterization of waste reception Leaching test of a solid waste or solid initially generated by a solidification method.

Athanasios KK, Evangelos AV, Voudrias P (2007) Cementbased stabilization/solidification of oil refinery sludge: Leaching behavior of alkanes and PAHs. J. Hazard. Mater. 148: 122-135.

Athanasios KK, Vasileios P, Ioannis N, Eleni P, Simone B, Evangelos AV (2008) Characterization of stabilized/solidified refinery oily sludge and incinerated refinery sludge with cement using XRD, SEM and EXAFS. J. Environ. Sci. Health. Part A: Tox. Hazard. Subst. Environ. Eng. 43: 1144-1156.

Barna R, Rethy Z, Tiruta-Barna L (2005) Release dynamic process identification for a cement-based material in various leaching conditions. Part I. Influence of leaching conditions on the release amount. J. Environ. Manag. 74: 141-151.

Belebchouche C, Moussaceb K, Tahakourt A, Aït-Mokhtar A (2015) Parameters controlling the release of hazardous wastes $\left(\mathrm{Ni}^{2+}, \mathrm{Pb}^{2+}\right.$ and $\left.\mathrm{Cr}^{3+}\right)$ solidified/stabilized by Portland cement CEM-I. Mater. Struct. 48: 2323-2338.

Chen QY, Tyrer M, Hills CD, Yang XM, Carey P (2009) Immobilisation of heavy metal in cement-based solidification/stabilization: a review. Waste Manag. 29: 390-403.

Conner JR (1990) Chemical fixation and solidification of hazardous wastes. Van Nostrand Reihold, New York, USA, $682 \mathrm{p}$.

Delmi MMY, Aït-Mokhtar A, Amiri O (2006) Modelling the coupled evolution of hydration and porosity of cement-based materials. Constr. Build. Mater. 20: 504514.

EU Council (2003). Council Decision 2003/33/EC of 19 December 2002 establishing criteria and procedures for the acceptance of waste at landfills pursuant to Article 16 of and Annex II to Directive 1999/31/EC. Official Journal of the European Communities L 11: 27-49.

Gallego JLR, García-Martínez MJ, Llamas JF, Belloch C, Pelaez AI, Sanchez J (2007) Biodegradation of oil tank bottom sludge using microbial consortia. Biodegradation 18: 269-281.

Imyim A, Tiruta-Barna L, Barna R, Méhu J (2000) Prediction of inorganic pollutant release from various cement based 
materials in disposal/utilization scenario based on the application of a multi-parameter leaching toolbox. Waste Manage. Ser. 1: 318-324.

Järup L (2003) Hazards of heavy metal contamination. Br. Med. Bull. 68: 167-182.

Kazuyuki S, Yoshiro O (2008) Leaching characteristics of stabilized/solidified fly ash generated from ash-melting plant. Chemosphere 71: 922-932.

Minocha AK, Jain N, Verma CL (2003) Effect of organic materials on the solidification of heavy metal sludge. Constr. Build. Mater. 17: 77-81.

Moussaceb K, Aït-Mokhtar A, Merabet D (2012) Influence of leaching conditions on the release kinetics of lead, chromium and nickel from solidified/stabilized cementitious materials. Environ. Technol. 33: 2681-2690.

Moussaceb K, Belebchouche C, Aït-Mokhta A, Merabet D (2013) Evaluation of the impact of Nickel, Chromium and lead contained in effluents of an industrial unit by the process of stabilization/solidification using hydraulic binders. Int. J. Environ. Res. 7: 485-494.

Nestle N, Zimmermann C, Dakkouri M, Niessner R (2001) Action and distribution of organic solvent contaminations in hydrating cement: time-resolved insights into solidification of organic waste. Environ. Sci. Technol. 35: 4953-4956.

Polettini A, Pomi R, Sirini P, Testa F (2001) Properties of Portland cement stabilized MSWI fly ashes. J. Hazard. Mater. 88: 123-138.

Tiruta-Barna L, Imyim A, Barna R (2004) Long-term prediction of the leaching behavior of pollutants from solidified wastes. Advan. Environ. Res. 8: 697-711.

U.S.E.P.A. (1994) Toxicity Characteristic Leaching Procedure (TCLP), Method 1311, Solid Waste Characterization Manual SW-848, Test Methods for Evaluating Solid Waste, Physical/Chemical Methods. Athens, Georgia, USA. (http://www.epa.gov).

Van Der Sloot HA, Meeussen JCL, Van Zomeren A (2006) Developments in the characterization of waste materials for environmental impact assessment purposes. J. Geochem. Explor. 88: 72-76.

Van Der Sloot HA, Van Zomeren A, Meeussen JCL, Seignette P, Bleijerveld R (2007) Test method selection, validation against field data, and predictive modelling for impact evaluation of stabilized waste disposal. J. Hazard. Mater. 141: 354-369.

Voglar GE, Lestan D (2013) Equilibrium leaching of toxic elements from cement stabilized soil. J. Hazard. Mater. 246-247: 18-25.

Zhang J, Liu J, Li C, Nie Y, Jin Y (2008) Comparison of the fixation of heavy metals in raw material, clinker and mortar using a BCR sequential extraction procedure and NEN7341 test. Cement Concrete Res. 38: 675-680. 